\title{
Anthós
}

\section{Understanding Visibility of Queer Bodies Through Discursive and Materialist Schools of Thought}

\author{
Evelyn Birnbaum \\ Portland State University
}

Follow this and additional works at: https://pdxscholar.library.pdx.edu/anthos

Part of the Feminist, Gender, and Sexuality Studies Commons Let us know how access to this document benefits you.

\section{Recommended Citation}

Birnbaum, Evelyn (2021) "Understanding Visibility of Queer Bodies Through Discursive and Materialist Schools of Thought," Anthós: Vol. 10: Iss. 1, Article 6.

https://doi.org/10.15760/anthos.2021.10.1.6 


\section{Understanding Visibility of Queer Bodies Through Discursive and Materialist Schools of Thought}

Evelyn Birnbaum

In this paper, I will be analyzing "Queer Visibility in Commodity Culture" by Rosemary Hennessy along with Gender Trouble and Bodies That Matter by Judith Butler. My argument is that Butler and Hennessy have different ideas about how queer visibility is conceptualized based on their different schools of thought: discursive versus materialist. ${ }^{1}$ To prove this, I will discuss Hennessy and Butler's viewpoints on visibility and how well both of their arguments fit with their respective evidence. I will also consider their arguments alongside contemporary viewpoints on the issue such as gender dysphoria ${ }^{2}$ being a material experience working in tandem with the discursive experience of gender ideation ${ }^{3}$ that is influenced by societal factors such as social media. The purpose of my review is not only to look at some older texts and analyze where the discourse community differed in the past but to ultimately use the texts to show how the field has evolved because of and in spite of these differences. My paper aims to contribute to the scholarship on queer theory, which is gaining increasing prominence in academic circles, by clarifying the differences between materialist and discursive schools of thought, recognizing the strengths and weaknesses of both positions, and offering a contemporary-focused, lesser-heard perspective.

Butler is a philosophical thinker who draws inspiration from Simone de Beauvoir's idea of a woman as 'Other', the idea that women are never considered a subject, are defined in relation to man, must become a woman, and, essentially, become 'other' (Bodies That Matter, 1), as well as Michel Foucault's "regulatory power", an idea which looks at how structures of language and literature affect the materiality of "sex" as an "ideal construct which is forcibly materialized through time" and through the influence of society (Gender Trouble, 7-8). Butler argues that gender is performative. People aren't born with gender; they're merely born with biological sex (Gender Trouble, 6). She develops this idea further in Bodies That Matter by saying people do not wake in the morning and

\footnotetext{
${ }^{1}$ In this paper, I define discursive as the philosophy of societally-shaped semantic understandings of the body, in order words, the idea that words can define us as much as we define them, whereas the materialist philosophy insists on the existence of the body as a physical and material reality that interacts with but is not merely defined by discourse.

${ }^{2}$ Gender dysphoria is the feeling of discomfort in one's body in terms of the disconnect between the sex they were assigned at birth and their gender. Many transgender and nonbinary people will experience this in some capacity and can be the primary reason for medical transitioning.

${ }^{3}$ Gender ideation is the societal process of defining what a gender looks like through literature, media, etc., and further, how that gender is perceived by society.
} 
put on "that gender for the day," - it is not a deliberate act — but goes on to say, gender is socially constructed in that definitions of genders and how to express oneself as a certain gender is taught/learned from society $(\mathbf{x})$. Butler believes verbal discourse - a way of thinking and producing meaning via language - is a large part of the social construction of gender norms and "governs the materialization of bodies" i.e. governs how we see and relate to our anatomy knowing that gender is a construct and not just a given based on one's 'sex' (Bodies That Matter, 3). In this sense, language is a limiting factor in the visibility of women and queer people, and to achieve "political" visibility, the language of the discourse must be altered. Butler goes so far as to complicate even the distinction between "sex" and "gender", arguing that sex, like gender, is socially inscribed. Of course, where she sees performing gender as a subconscious everyday act, this is a heteronormative/cisnormative notion that ignores that for transgender, genderfluid, and other queer people, there is a very conscious act of performing gender, whether as a means of activism as Hennessy suggests (i.e. subverting heteronormativity in commodity culture by wearing clothing that defies gender stereotypes) or just as a means to exist as a transgender/nonbinary person.

The Marxist theorist Rosemary Hennessy's particular critique of Judith Butler's works in "Queer Visibility in Commodity Culture," targets Butler's approach to conceptualizing visibility. Hennessy argues against Butler's philosophical thesis by saying that her queer theory fetishizes the material human, and discourse cannot be the only means of enacting change in the system because it is a social struggle, not a semantic struggle. Essentially, we cannot just simply change our language to reflect how we understand gender because that, too, will only be a "limited victory" (Hennessy, 32). One way we can understand this is that as much as a group tries to reclaim language and words that have been used against them in the past, those words can still be used against them in the future because they have that history and still exist in the same system. Furthermore, thinking that this problem is only semantic ignores the actual material struggles of discrimination to people who do not pass as a certain gender, or the intersectionality of queer visibility in BIPOC communities, or the fact that capitalism is the root of these problems, not just the language that we created within the capitalist system.

Moving past the semantics, Hennessy uses the concept of commodity fetishism ${ }^{4}$ to explain the lack of visibility for queer bodies. In her essay, she does

${ }^{4}$ Commodity fetishism is the idea that inanimate material goods have a stronger social relationship with the consumer than the consumer has with other living people i.e. that a shirt with a gay pride flag better represents the movement, in the consumer's eye, than all of the people who make up the movement. In that sense, the consumer is fetishizing or exoticizing the product by not 
not just critique the works of Butler, but of many different scholars and discourse community members, arguing that for those participating as a consumer in capitalist societies/economies, "the visibility of sexual identity is often a matter of commodification, a process that invariably depends on the lives and labor of the invisible others", i.e. the people that get recognition for a queer product that subverts hegemony and creates visibility of sexual identity in a capitalist society is the owners of the company that sells the product or the consumers instead of the individual laborers who are doing the manual labor of sewing, building, crafting, etc. (31). Hennessy objects to activists' calls to action, saying, "visibility in commodity culture is in this sense a limited victory for gays who are welcome to be visible as consumer subjects but not as social subjects," going on to list rebellious queer clothing as one of these limited victories for activism (32). Her call to action is, instead, to dismantle the system in order to effectively stop these oppressions.

Hennessy and Butler share a research concern that Hennessy articulates well in the first sentence of her essay: "how visibility is conceptualized matters." However, both scholars approach conceptualization in differing ways based on their preference for the material or discursive influence and experience. Hennessy understands the concept of visibility to be about individual material experience and "detecting and displaying empirical bodies" (38). As a current example of material experience, we can think of how makeup has developed as an expression of art through its current non-gendered use on all peoples whereas decades ago it was used as a defining characteristic of femininity and the only time it was an expression of art was in drag. This influence is material because it was the historical observation of visible bodies putting on makeup that contributed to the formation of makeup as an art form.

According to Butler's discursive understanding, people internalize gender identity, or "personhood", based on societal conditioning because social context influences their ideas of what it means to be a certain gender, they thus perform an internalized identity consciously, and subconsciously, in everyday life (Gender Trouble, 17). In this sense, Butler believes visibility is limited to a taught/learned experience, social norms, and discourse/language. Butler's idea to change the visibility/representation starts with language, as she believes language can "reveal or distort what is assumed to be true about" women, queers, etc (Gender Trouble, $1)$.

Hennessy understands Butler's discursive influence as the idea that people dressing in drag is a bad parody of gender expression reality instead of its

thinking about who made the product, and the human labor that went into its creation, or who the product might be representing as a whole, including and other than just the consumers of it. 
own gender expression. "As parody, drag belies the myth of a stable self pre-existing cultural codes or signifying systems. Against the dominant reading of drag as a failed imitation of the 'real thing,' Butler posits it as a subversive act" (Hennessy, 38). Because of that understanding, Hennessy rebuts and argues that seeing drag as a bad parody separates it from historical processes and the struggles that produced it as a form of gender expression (44). Furthermore, regarding drag as a parody allows it to be understood as a copy of heteronormative gender expression that can be mass-produced and fetishized as a means of rebellion. Marx's idea of commodity fetishism as a form of action that incites change is a major thematic critique in Hennessy's essay. She disagrees with the action as it separates humans from their labor and creates an "invisible other" because the commodity/product becomes "exotic" in its separation from human labor and this exotic view of a product makes it much easier to make a profit from in capitalism as it increases its exchange value (Hennessy, 53).

However, while Hennessy does make some important points in her critique of Butler's works throughout the paper, there are a few instances where she misreads Butler's works, the most important of which is the aforementioned controversial idea of Butler's that drag is a bad copy of heterosexual gender norms. Hennessy calls out this idea that "at one point [Butler] admits that gender parody in itself is not subversive" (40). However, Hennessy uses "Queer Visibility in Commodity Culture" to critique both of Butler's books, the latter of which corrects the idea by saying that "hegemonic heterosexuality is itself a constant and repeated effort to imitate its own idealizations", and therefore, drag is subversive in its attempt to imitate the idea of heterosexuality imitating itself (Bodies That Matter, 125).

It appears Hennessy is critiquing Butler in order to discredit her discursive queer theory. Her criticism of Butler's works culminates in the idea that seeing identity as performative fetishizes visibility and "conceals the social relations new urban gay and queer identities depend upon" because it puts value in the objects created and used to "disrupt normative conceptions of sexuality" rather than putting value in the social relations between individuals and objects $(36 ; 54)$. It uses clothing as a means of activism to subvert heteronormativity and cisnormativity rather than put value in the people that make the products used to do the subverting. To break it down, buying a rainbow pride flag from Amazon to put up in a school to show that it is an LGBTQ+ friendly space is an act of activism that promotes queer visibility but it is still ignorant of the human labor going into the commodity (the flag) in that Amazon is the middle-man that makes a profit from the sale and does not acknowledge the human labor used to make that flag, or at least makes the consumer ignorant of it aside from the seller's name on the listing. This is an 
example of commodity fetishism, and Hennessy deems Butler's idea that identity is performative as a fetishization of queer visibility because it makes actions of a trans person dressing their gender or someone doing drag into some form of activism against heteronormativity that relies on commodity culture, instead of seeing the actions for what they are: existence and art.

Hennessy does make some valid points in that it is important to recognize the materiality of our bodies, and theorizing/making queer visibility about semantics does take away from the actual physical issues queer people face, especially queer BIPOC. However, Butler also makes a valid argument about how we perform gender identity, and how we are influenced by societal creations like the media. The reason a large percentage of people who identify as females are so performatively femme is partly because magazines and adverts narrate the idea of what it means to be feminine, and vice versa with masculinity. This means trans or nonbinary persons can find themselves overperforming gender identity because they have internalized ideas and images about these genders. The problem with assuming gender based on an understanding of Butler's "gender performativity" is that it leads to the possibility of misgendering because it centers our idea of gender on what society sees, and society is, on the whole, oppressive. If a trans man isn't passing and chooses to wear stereotypically effeminate clothing, he may be misgendered because there is no place in society for a non-passing trans man to be viewed as the man he is. Transgender people must over-perform to avoid being misgendered, and there is a fear of misgendering because being called the wrong pronouns can or likely will validate any insecurities one may have in their understanding of themselves, even, and especially if it can be recognized as intentional misgendering.

In Bodies That Matter, Butler argues that bodies aren't material by themselves; materiality is a product of psychoanalysis (54). I take this to mean that materiality is a product of our understanding of bodies from the bias of a patriarchal white supremacist society: we do not just understand our bodies as material through an instinctual impulse upon our birth. This understanding of materiality, while entirely different from Hennessy's, fits with Butler's thesis of discursive influence that we learn to perform our gender, learn our materiality through societal influence, learn our place in society based on the language and the rhetoric that we define and defines us, and are visible because of our performativity. If we do not perform in socially acceptable ways, we may not be acknowledged, or we may be treated negatively, as it can be seen as a subversive act to misperform gender identity.

I think a key issue with Hennessy and Butler's differing opinions, besides their different schools of thought, is the fact that they do not agree on 
who is affected most in this area of discourse. Butler tends to focus on political, feminist, queer, and lesbian women in basing her understanding of the conceptualization of visibility. She recognizes "the category of 'women' as the subject of feminism" (Gender Trouble, 2). In that sense, it isn't hard to understand why Hennessy argues that Butler's local view of queer history limits her understanding of the oppressed to those in "the new bourgeois professional class" which can include queers - a limited number of powerful lesbians, and flamboyant gays that are now ${ }^{5}$ passing gender norms due to the heterosexual sex-gender system incorporating queers' once-disapproved gender-expression into popular culture via magazines and such $(41 ; 62)$.

I would say this limited representation of queers remained relatively unchanged in mainstream discourse until the past few years when people outwardly started to reject the poor queer representation that had been limited to stereotypes held over from decades prior, which is another issue that arises in critiquing both Hennessy and Butler. These theories are over 30 years old. Current Marxist theorists like Sue Caldwell recognize that Butler's focus on women as the key players of gender politics is an old concept, moreover, the way queer people understand Marxist thought has transformed (Caldwell, 5:35). People feel gender dysphoria when looking at themselves, which is a material experience and not based on societal influence, and yet, we learn to present ourselves on the gender spectrum in relation to what we are told is normal for a certain type of gender expression or according to what words we let categorize and define us, and that is discursive (Caldwell, 20:40-22:48). Furthermore, people can know if they are trans or nonbinary from a young age, and they can internalize what, if any, gender they feel represents them-even if they have a different anatomical presentation - because they know instinctively what is being targeted to the gender they identify with even if they do not pass biologically yet.

Rosemary Hennessy and Judith Butler both make valid arguments, and I think it's interesting that, in contemporary times, their ideologies can both be valid without having to stand firmly in one school of thought or the other (discursive or materialist). Their primary disagreement was their belief that only one school of thought was correct, and while I do agree that only considering the queer visibility issue to be of semantics is restrictive, it's also important to acknowledge the impact public discourse has had on our gender identity, especially now that it's constantly at our fingertips with the evolution of technology. It's going to take a collective effort from both schools of thought to create enough change in our current system to dismantle capitalism and the commodity fetishism it necessitates and adopt a system free of all oppression.

\footnotetext{
${ }^{5}$ In 1990 when Hennessy's critique was written this was not quite the case.
} 


\section{References}

Butler, Judith. Bodies That Matter: On The Discursive Limits of "Sex." New York: Routledge, 1993. Butler, Judith. Gender Trouble: Feminism and the Subversion of Identity. New York: Routledge, 1990.

Caldwell, Sue. "Going beyond the binary: Marxism, gender and trans politics." YouTube, uploaded by swpTvUk, 9 Aug. 2017, https://youtu.be/WxEyksnqSQY

Hennessy, Rosemary. "Queer visibility in commodity culture." Cultural Critique 29 (1994): 31-76. 